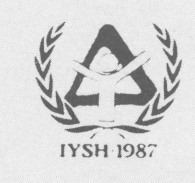

\title{
NOTAS SOBRE UNA ARQUITECTURA POBRE
}

\author{
Carlos González Lobo, Arquitecto \\ Facultad Arquitectura UNAM \\ (México)
}

\begin{abstract}
... "La ideología está en la elección de los campos de investigación hacia los cuales se inclina la atención de quienes producen ciencia, y más aún en la orientación dada a la aplicación de los conocimientos científicos, o sea a la tecnología. ...Pero si la orientación de la ciencia y la técnica está históricamente condicionada, la ciencia en sí y lo esencial de sus aplicaciones ya comprobadas por la experiencia constituyen una ampliación de la capacidad del hombre para pensar y actuar de permanente validez."
\end{abstract}

Celso Furtado: Creatividad y dependencia.

La arquitectura en la realidad actual, oscila entre la producción de objetos monumentales y simbólicos, como expresión del Poder, dentro de la cultura de la clase dominante: y la producción masiva de espacio habitable, que como mercancía se dirige a un usuario potencial (y cautivo), que a través del consumo, reproduce la ideología del grupo dominante a la vez que desarrolla el ciclo económico de la acumulación capitalista. En este campo "arquitectónico", se desarrollan las teorías, críticas e interpretaciones históricas, que nos forman y condicionan como: arquitectos, usuarios o promotores.

Pero al margen de esta Arquitectura, existe una producción de espacio habitable "otro", precario, desordenado, en proceso de irse haciendo permanentemente, que está al menos ignorado por la teoría arquitectónica establecida, pero en ella habita (su vida, sus ilusiones y sus luchas), la mayoría de la raza humana.

Cuando por el proceso de desarrollo de las fuerzas productivas y la planetarización de la Economía-Mundo Capitalista, esta producción espacial en acelerado crecimiento, se convierte en demanda y motivo de presiones de los movimientos sociales urbanos y revindicativos de los pobres eñ general, la atención institucional a esta arquitectura, se hace mediante la translación de las normas edificatorias, conceptuaciones teóricas y sistemas proyectuales, provenientes de la Teoría Arquitectónica establecida imponiénose ideológicamente: normas, estándares y programas "decentes" (léa- se: como del "primer mundo") que se enfrentan a la escasez de recursos, lográndose programas edificatorios: "de ricos para pobres", así hoy en México post-sísmico vemos la aparición de vecindades pos-modernas, insuficientes para la habitabilidad de los usuarios, en términos de espacio construido (son pobres) pero realizadas a través de constructoras y análisis tecnológicos de "pánico sísmico", costosos pero muy seguros y aprovechando el viaje para parchear la fachada urbana con costosas e inútiles portadas que evocan a Krier, Portman o Graves, los arquitectos, tienen su cultura bien actualizada como se ve: el edificio es pues, "rico" en su concepción, aunque "pobre" en su constitución; esto nos expresa la dependencia cultural de esa "arquitectura".

Estas notas pretenden, entonces, elaborar una teoría propia de la arquitectura de los pobres: arquitectura de países y economías pobres que recuperen la cultura regional, minoritaria y la identidad y el arraigo de los pobres, para con ellos... hacer arquitectura que ajuste la (su) necesidad con su posibilidad, objetivas y concretas. "Arquitectura pobre para los pobres."

Escribo estas reflexiones, en la Ciudad de México, una de las más grandes, extendidas y contaminadas del mundo: dieciocho millones de habitantes que amenazan con rebasar los 30 millones en el año 2000 , lo que implicará que, en mi ciudad, hay que construir, en medio 
de la crisis económica más sombría y con una deuda externa impagable, una ciudad de tamaño igual al actual que contiene el patrimonio inmobiliario acumulado en los últimos 400 años y esto hay que hacerlo en sólo trece años (!!?).

Enunciaré, inicialmente, las cuatro cuestiones que pretende atender la preocupación que oriente hacia dónde debe ir nuestra arquitectura hoy:

1. ¿QQué arquitectura, objetivamente, necesitan y pueden pagarse, los asalariados de bajos ingresos, los desempleados, las organizaciones independientes (sindicales o revindicativas urbanas) y los grupos de campesinos pobres; ya que estos constituyen la mayoría de la población? ¿Y cómo debemos: concebirla, proyectarla y construirla, si pretendemos honesta y solidariamente contribuir como asesores técnicos e investigadores universitarios, a ayudar a estos grupos a resolver sus necesidades urbano arquitectónicas, aquí y ahora; así como a prever e inducir su futura solución?

2. ¿Es posible implementar, mediante la investigación sistemática y la experimentación en precario, de los grupos de asesoría técnica independientes y universitarios; las técnicas de distribución espacial, las técnicas constructivas y las técnicas de instalaciones y ecotécnicas, que se ofrezcan como alternativas apropiadas a la necesidad y a la posibilidad reales de los grupos antes descritos; y que sean fácilmente apropiables por los sujetos usuarios de esos grupos?

3. ¿Cuál sería el modo de hacer compatible esta "arquitectura pobre" afín con la realidad de un país capitalista, periférico (subdesarrollado, dependiente, de consumo dirigido, etc.) como México, con las iniciativas de planeación y constructivas "de interés social" del Estado, con las incipientes organizaciones autogestivas populares; y como incidir para mediar entre sus modos y discursos?



Materiales autóctonos. Soluciones mejorables

(C) Consejo Superior de Investigaciones Científicas Licencia Creative Commons 3.0 España (by-nc)
4. ¿ ¿Cómo integrar en una teoría coherente, las formulaciones tipológicas y metodológicas de corte funcional-constructivista, el discurso significante que recupere y preserve la cultura popular y nacional de los usuarios diversos, la imbricación de las intervenciones en un medio urbano pre-existente, y las investigaciones espaciales y formales de las vanguardias?

En una primera aproximación a esas respuestas, enunciaré previamente unas tesis sobre una arquitectura pobre:

http://informesdelaconstruccion.revistas.csic.es 


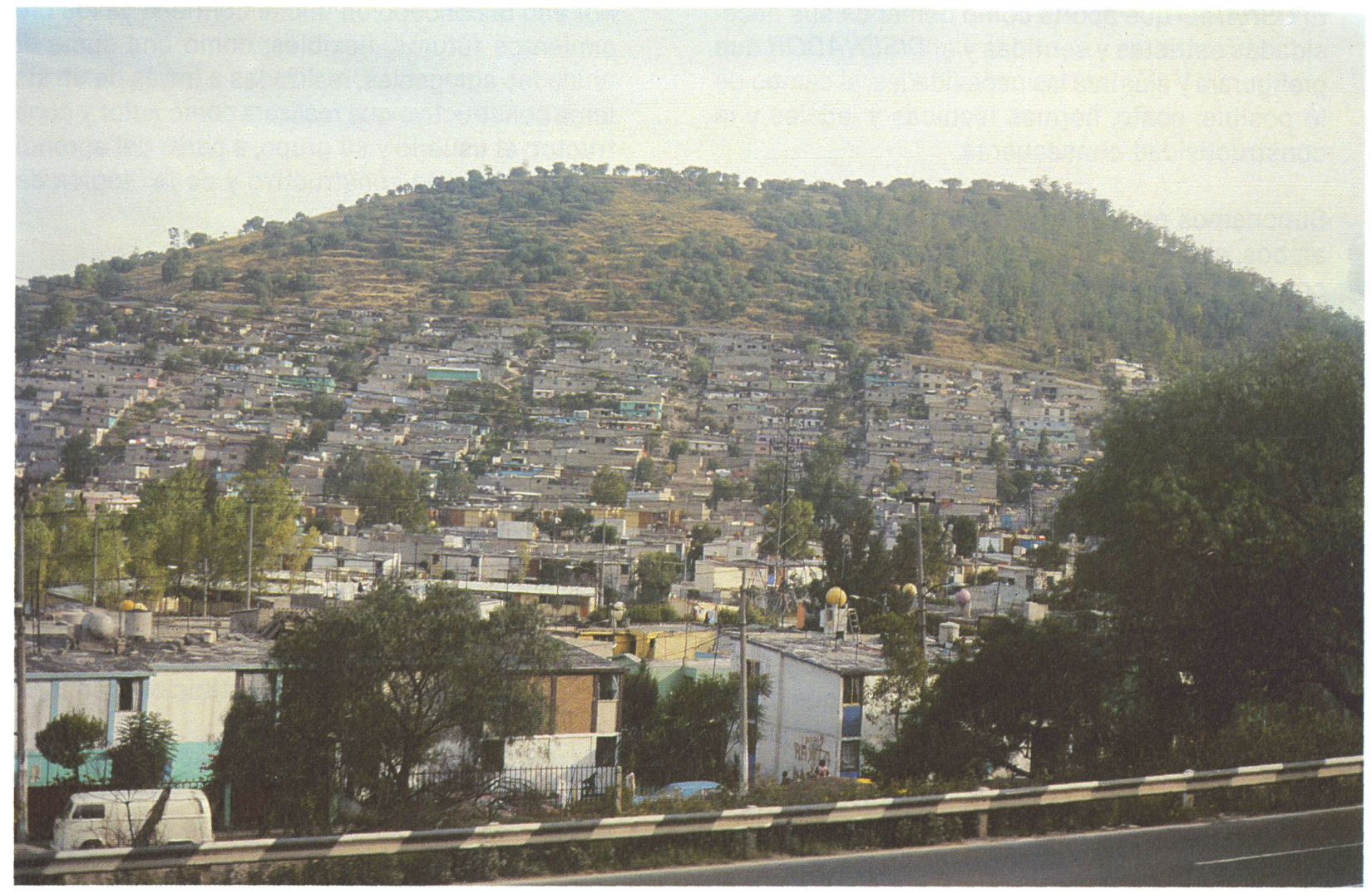

\section{1. ${ }^{\text {a }}$ La habitabilidad como centro}

El objeto arquitectónico es en estricto, el albergue espacial de las actividades humanas específicas, articuladas entre si por una manera social de entenderlas (conocerlas, poderlas e imaginarlas) en un momento histórico dado. Dicho albergue permite, restringe, posibilita o inhibe, el despliegue de la vida humana que como habitabilidad, requiere (o demanda) de alojarse en un espacio (habitable), que se diferencia del espacio "inextenso" porque: está ahí, en un lugar "habitado" urbano o rural en el que queremos o podemos vivir por un lado; y porque es ahí con su configuración especifica, que alberga nuestra necesidad y se apropia de nuestra demanda, identificándola rigurosamente con su forma espacial, construida y significante, por el otro. Por último el albergue podría (es deseable) potenciar dicha actividad, intensificando su calidad de uso y elevando consecuentemente la calidad de vida de el (o los) habitantes-usuarios.

De esta manera, en rigor concebir y proyectar ese albergue, consiste en dejar a las actividades (habitables) en libertad para apropiarse del espacio necesario, tanto en área, como en posición, así como para facilitar la articulación real (que los usuarios esperan o quieren) de las actividades entre sí, tanto en la necesidad conocida, como en la tendencia que dicha manera social de la actividad sugiera (1).

Dicha actividad, así entendida, es el motivo central del trabajo arquitectónico, supeditando los aspectos técnicos, formales y teóricos, al logro cabal (y amoroso) de dicho propósito que no es otro que el de albergar y estimular la actividad humana plena de los usuarios actuales y futuros.

Ninguna predeterminación: normativa, estilística o de la concepción cultural del diseñador debe imponerse sobre esto.

\section{2. ${ }^{\text {a }}$ La producción Autogestiva y dialogal}

2.1. Si admitimos que el objeto arquitectónico es producido por dos sujetos históricamente determinados: (2)

(1) Véase al respecto: J. Revueltas: Cuestionamientos e In tensiones. Edit. Era Mex. págs. n. ${ }^{\circ} 116$ y ss.

(2) Ver Tesis de las Linternas de la Arquitectura, México 1970. J. M. Davila et al. Revista Devenir, UM 
EI USUARIO que aporta como demanda sus necesidades estrictas y sentidas y el DISEÑADOR que prefigurará y ajustará las necesidades, al campo de lo posible: costo, normas técnicas y legales y la constructividad consecuente.

Suponemos por ello que del diálogo estrecho de ambos, el proyecto se irá afinando en progresivas correcciones, hasta volverse un documento técnico apto para construir "el edificio".

El resultado final expresará al usuario en cuanto a la satisfacción efectiva de sus necesidades en el campo de su posibilidad concreta, y el objeto resultante enriquecerá la cultura arquitectónica que expresa al diseñador y a la clase de que ambos se reclamen.

2.2. $Y$ considerando que la arquitectura popular (mayoritaria) se caracteriza por que está marcada por la escasez, la precariedad y la carestía, lo que obliga a concebir su producción: como un "estar haciéndose" en el tiempo, por etapas, coyunturalmente, según ritmos de acumulación, ahorro u oportunidad, diferenciales para los distintos usuarios.

Esta producción se orienta en nuestros paises desde dos perspectivas que chocan, se entrecruzan y ocasionalmente dialogan:

Por un lado la autogestión incipiente que, organizaciones sociales independientes tales como organizaciones de barrio, grupos organizados de colonos y campesinos y algunos sindicatos independientes, llevan a cabo para atender y resolver sus problemas espaciales ya sea a través de la lucha cotidiana contra las autoridades, que en muchos casos acaban por articularlos a organismos de control, reduciendo sus demandas a programas institucionales "de emergencia"; o bien esa autogestión incipiente y rudimentaria los conduce a tomar la edificación por su cuenta (autoconstrucción) para resolver: con sus medios, recursos y trabajo extraordinario, las carencias tanto de vivienda, como de urbanización y equipamiento: recreación, educación, salud y espacios para el intercambio. Y por otro lado los programas estatales de interés social para controlar, regular y mediar en las presiones sociales urbanas.

2.3. En ambos casos, los edificios generalmente sólo absorben en un momento de la demanda, como primera etapa que atiende a lo esencial de la implantación del uso en el sitio, por lo que los proyectos de esta arquitectura pobre, integran una práctica constructiva en el proceso permanente de complementación, ampliación y crecimiento.
Por ello la concepción inicial contiene ya los crecimientos futuros, flexibles; como una suma de unidades agregables, realizadas a través de un sistema constructivo que realizara como autor y constructor: el usuario y su grupo, a partir del aprendizaje del sistema constructivo y de la "lógica del proyecto «in albis»".

2.4. Y finalmente que en su producción definitiva, a los momentos autogestivos, solidarios y de lucha, se les imbrica con los trayectos de negociación, represión de las iniciativas y encausamientos hacia la normatividad institucional, con los límites intelectuales de una cultura dependiente.

Por ello, la formulación de esta arquitectura implica la concepción de lo necesario y posible, además del tanto dedicado a pedir de más, para la hora del diálogo, no necesariamente cordial y gentil entre los sujetos del proceso autogestivo, y los representantes del urbanismo institucional en turno.

2.5. Por último recordemos que la masa de objetos arquitectónicos, urbanos y de paisaje, en estricto, sólo son nuestros para su usufructo provisional, y que por lo tanto, el trabajo proyectual surgido del diálogo participatorio entre la comunidad usuaria y los proyectistas del grupo de apoyo técnico (como texto), se realiza sobre, entorno y junto a las obras edificadas preexisistentes en el sitio (contexto), y que la producción de objetos espaciales, si bien es consecuencia de una demanda socialmente generada (pretexto), obliga al diseñador a actuar como agente histórico frente y junto al demandante, para insertar con finura y agudeza la obra actual en la urdimbre histórica que supone el "hacer la ciudad" (como subtexto).

\section{3. ${ }^{a}$ Una tecnología alternativa, apropiada y apropiable.}

Si bien la arquitectura de los pobres tiene escasos recursos, cuenta con la fuerza de trabajo de los necesitados, en vias a organizarse para instrumentarla en la satisfacción de sus necesidades. Y esto que puede verse como una sobre-explotación de la fuerza de trabajo, es sin embargo un instrumento para la superación del estado de carencia en que "se existe", una manera de superarse y organizarse politica y culturalmente, a través del proyecto que el trabajo de autogestión en la edificación, genera sobre el individuo y el grupo, y una forma de "hacerse historia", (la de sus obras, como el Quijote).

En la brevedad de estas notas desarrollaré algunos puntos sobre este enfoque:

3.1. Buscar una tecnología tal, que garantice la supe- 
ración objetiva del productor y usuario, implica generar modelos técnicos que atiendan: por un lado a un uso eficiente y científico de los materiales, la geometría y el cálculo, lo suficientemente avanzado como para que sean viables a la escasez de recursos (tecnología apropiada); pero por otro lado dicha tecnología debe ser captada y practicada por el usuario sin formación específica; así como ancianos, mujeres y niños que por igual participan de la edificación; debe estimular su comprensión y creatividad (tecnología apropiable).

3.2. Por ello nuestra investigación ha girado en torno a las tecnologías intermedias aptas para integrar trabajo artesanal y materiales regionales junto a métodos de prefabricación en sitio, producción sistematizada y optimización de los recursos materiales a costa si es necesario de insumos mayores de trabajo humano. Por ejemplo sin agotar el tema, sistemas tecnológicos que como trabajo lo- gren del productor y el usuario: un cabal desarrollo cognoscitivo, un adiestramiento del trabajo en comunidad de la mano de obra, que optimice la ocupación y eficiencia de la fuerza de trabajo por un lado y la relación costo-beneficio por el otro; los hemos llamado tecnologías de espacio máximo y costo mínimo ya que aumentan en las dos direcciones la productividad humana.

3.3. Y finalmente tecnologías progresivas apropiables que racionalizan el tiempo social histórico, ya que estimulan la participación, la autogestión y la desalienación, conviertiendo a sus usuarios en actores: imaginativos y solidarios de su propia historia, que se materializa en la ejecución escrupulosa de sus sueños, a través de su esfuerzo, organización y la vinculación del conocimiento científico y universitario que como apoyo técnico independiente los integra a un panorama amplio y universal de la cultura humana.

\section{publicaciones del I.E.T.c.c.}



Modelos reducidos. Método de cálculo

H. Hossdorf, Ingeniero Civil

La técnica de los ensayos en modelos reducidos de

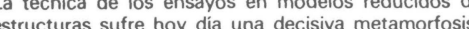
Hasta hace poco era un medio más bien de artesania, que no siempre era tomado en serio por los nia, que no siempre era tomado en serio por los miento resistente de las estructuras complejas y a que se acudió las más de las veces, como a un ultimo remedio debido a sus indiscutibles insuficiencias. Sin embargo, en poco tiempo y gracias a su conexión con los ordenadores digitales, se ha transconexion con los ordenadores digitales, se ha transque no puede quedar a un lado en la práctica diaria del Ingeniero Proyèctista.

Un volumen encuadernado en cartoné plastificado con lomo de tela, de $17 \times 24 \mathrm{~cm}$, compuesto de 250 páginas, 158 figuras y fotografias.

Precios: 1.800 ptas.; \$ USA 26.00

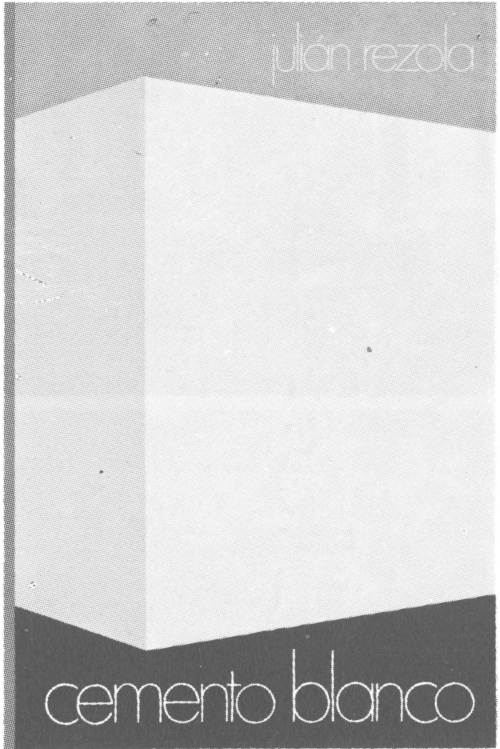

\section{Cemento blanco}

Julián Rezola

Ingeniero Químico Dipl. I. Q. S.

Sabido es que existe una extensa y documentada bibliografía sobre el cemento gris: en cambio, no puede decirse lo mismo acerca del cemento portland blanco, ya que los escritos existentes se refieren tan de aquél.

El autor nos ofrece sus profundos conocimientos y su larga experiencia tanto en laboratorio como en fabricación.

La parte descriptiva del libro se complementa con gráficos, diagramas y fotografias de gran utilidad, graficos, diagramas y fotografias de gran utilidad, este aglomerante.

Un volumen encuadernado en cartoné policerado, de $17,4 \times 24,3 \mathrm{~cm}$, compuesto de 395 páginas. numerosas figuras, tablas y ábacos.

Precios: España, 1.700 ptas.; extranjero, \$ 24.



La presa bóveda de Susqueda

A. Rebollo,

Dr. Ingeniero de Caminos

El esfuerzo del constructor de presas se sitúa, por su pretensión de perennidad, a contracorriente de las tendencias de la civilizacion actual, caracterizada por to fungible. Pueden evocarse las 10.000 grandes presas en funcionamiento o en construcción que estan envejeciendo $y$ reclaman los cuidados gerontológicos para mantener y perfeccionar su servicio garantizar su inalienable pretensión de perennidad. En la medida en que todas nuevas obras, grandes o pequeñas, son portadoras de riesgos ecologicos $y$, a veces, catastroficos, que aumentan con el envejecimiento, la gerontologia de las presas es todo un emplazo. La acción adelantada de Arturo Rebollo en este terreno marca un camino revir para todos los que aman su propia obra con

Un volumen encuadernado en cartone plasificado Un volumen encuadernado en cartoné plastificado 408 ṕ́gins, 330 figur $y$ for

Precios: 1.700 ptas.; extranjero, \$ USA 24.00. 